\title{
Ontogeny of step-through passive avoidance learning in domestic chicks: Effects of prepunishment training and cue distinctiveness
}

\author{
JAMES F. ZOLMAN and BRUCE A. MATTINGLY \\ Department of Physiology and Biophysics, Medical Center, University of Kentucky \\ Lexington, Kentucky 40536
}

\begin{abstract}
In three experiments, 1 - and 4-day-old chicks $(\mathrm{N}=96)$ were first trained to move from one compartment into another for heat reward, and then, following 1, 24, or 48 prepunishment trials, the chicks' step-through responses were punished with aversive wing-shocks during 24 passive avoidance (PA) trials. The major finding of these experiments was that the age dependency of PA learning of the young chick depends upon both the number of prepunishment trials and the cue differences between the safe and shock compartments. The 1-day-old chick showed an improvement in PA learning as both prepunishment trials and cue differences were increased, but the 4-day-old chicks' PA learning was retarded by increasing the number of prepunishment trials when either identical or distinct cues were in the two compartments. These PA results suggest that the 1-day-old chick, as compared with the 4-day-old chick, is deficient in learning, or detecting changes in, stimulus- and/or response-reinforcement contingencies.
\end{abstract}

Many studies have reported that infant and weanling rats are inferior to adult rats in passive avoidance (PA) learning (see Campbell \& Coulter, 1976, for a review). In most rodent PA tests, prepotent stepdown or step-through (cross-over) responses have been punished (e.g., Riccio \& Schulenberg, 1969; Schulenberg, Riccio, \& Stikes, 1971; Wilson \& Riccio, 1976), and, consequently, only limited prepunishment training has been necessary. Recently, the agedependency of PA learning of the developing chick has been found to be related specifically to the amount of training given before punishment. After only a few prepunishment trials, 1-day-old chicks suppress responding in key peck and runway PA tests significantly less than do 4-day-old chicks, but when many prepunishment trials precede PA testing, both 1 - and 4-day-old chicks learn quickly to suppress their keypeck or running responses when punished (Mattingly \& Zolman, 1980).

Although the effect of prepunishment training on the age dependency of PA learning in mammalian species has not yet been determined, Wilson and Riccio (1976) have reported that 15-day-old rats

This research was supported by Grant MH 24260 from the National Institute of Mental Health and by NIMH Predoctoral Fellowship 1 F31-MH 07306 to B. A. Mattingly. We are grateful to J. E. Spivey and T. R. Zentall for their helpful comments on this manuscript. B. A. Mattingly is now at the Department of Psychology, Morehead State University, Morehead, Kentucky 40351. Requests for reprints should be sent to James F. Zolman, Department of Physiology and Biophysics, Medical Center, University of Kentucky, Lexington, Kentucky 40536. learned PA as quickly as 30-day-old rats in a stepthrough task when the cue differences between the safe and shock compartments were increased. Agerelated deficits in PA learning had been found previously, using the same apparatus but without the additional cues (Riccio \& Schulenberg, 1969; Schulenberg et al., 1971). Taken together, these studies with young chicks and rats indicate that by manipulating the prior number of reinforced trials, and perhaps cue distinctiveness, age-dependent differences in PA learning during ontogeny can also be manipulated. The purpose of the present study was to determine both the effects of prepunishment training and cue distinctiveness on the emergence of age-dependent changes in step-through PA learning of the young chick.

\section{EXPERIMENTS 1 AND 2}

After a few prepunishment training trials, infant and weanling rats are usually inferior to adult rats in step-through PA learning. The purpose of Experiments 1 and 2 was to determine whether age-dependent differences in step-through PA learning would be found in the young chick after both minimal and extended prepunishment training. Therefore, 1- and 4-day-old chicks were first trained to move from one compartment into another for heat reward and then, following either 1 or 24 prepunishment trials, all subsequent step-through responses of the chicks were punished by wing shock. 


\section{Method}

Subjects and rearing procedures. Forty-eight Vantress $\times$ Arbor Acre chicks were incubated and hatched at $37^{\circ}-38^{\circ} \mathrm{C}$ and $58 \%$ $60 \%$ relative humidity. Each chick was removed from the dark hatching incubator and banded within $4 \mathrm{~h}$ after hatching. The chicks were reared in groups of $10-12$ in white Plexiglas brooder compartments $(56 \times 33 \times 23 \mathrm{~cm})$ in a $35^{\circ}$ room. Food and water were available ad lib, and the brooder room was illuminated with fluorescent light from 6 a.m. to 11 p.m. In Experiment 1, 12 chicks began testing when 1 day old $(22.5 \mathrm{~h} ; \mathrm{SD}=.87)$, and another 12 chicks began testing when 4 days old $(99.4 \mathrm{~h} ; \mathrm{SD}=2.06)$. In Experiment 2, 12 chicks also began testing when 1 day old (23.1 h; $\mathrm{SD}=.86$ ), and another 12 chicks began testing when 4 days old (101.8 h; SD = 3.1).

Apparatus. Testing was done in a two-compartment box in a cold room maintained at $12^{\circ} \pm 2^{\circ} \mathrm{C}$. Each compartment was made of white Plexiglas and was cylindrical in shape $(15 \mathrm{~cm}$ diam $\times$ $29 \mathrm{~cm}$ high). An $8 \times 29 \mathrm{~cm}$ opening between the compartments was closed by a horizontally sliding, white Plexiglas door. The floor of the chamber was covered with an absorbant white animal pad. Heat reinforcement was delivered by a $250-\mathrm{W}, 115-\mathrm{V}$ redbulb infrared heat lamp located $33 \mathrm{~cm}$ above the floor of one compartment. An 18-cm, fluorescent bulb located above the compartments provided equal illumination in both compartments.

A constant current shock was supplied by a Grass stimulator (Model S48) connected to a Grass Stimulus Isolation unit (Model PSIU6). Shock was delivered to each chick through $12-\mathrm{mm}$ Wachenfeldt nickel silver wound clips attached to the wing web near the elbow of each wing. A $10-\mathrm{mm}$ female amphenol contact was attached to each wound clip. A pair of male amphenol contacts, connected to 25-ga insulated wires, completed the shock circuit when mated to the female contacts. The shock wires were suspended $1.5 \mathrm{~m}$ above the floor and centered between the two compartments so that the chick could move freely between the compartments.

During the intertrial intervals (ITI), the chick was held in a white Plexiglas cylinder $(20 \times 15 \mathrm{~cm})$ maintained at $33^{\circ} \pm 2^{\circ} \mathrm{C}$. Throughout testing, a white masking noise of $76 \mathrm{~dB}$ re $20 \mu \mathrm{n} / \mathrm{m}^{2}$ was delivered through a $10-\mathrm{cm}$ speaker located $1.6 \mathrm{~m}$ above the center of the box. All reinforcement and shock contingencies were programmed and controlled by electromechanical equipment.

Procedure. One-hour prior to testing, the chick was removed from its home brooder, wing-clipped, and then isolated in a white Plexiglas cylinder $(20 \times 15 \mathrm{~cm})$ in the brooder room. Following this isolation period, the chick was transferred to the testing room, connected to the shock wires, and placed in the ITI holding cylinder. After $15 \mathrm{sec}$, the chick was placed in the start compartment with the door closed, and $5 \mathrm{sec}$ later the door was open. When the chick entered the goal compartment, the door was closed and 8-sec heat reinforcement was delivered. Step-through latencies were recorded to the nearest $.01 \mathrm{sec}$ by a Hunter timer. Following reinforcement, the chick was returned to the ITI cylinder for $15 \mathrm{sec}$. The procedure was the same in both experiments, except that only one prepunishment trial was given in Experiment 1 and 24 prepunishment trials were given in Experiment 2. Passive avoidance testing began immediately following acquisition training, with the same procedure as in acquisition except that a 3-mA wing-shock of $3 \mathrm{sec}$ duration was given simultaneously with reinforcement onset. Passive avoidance testing continued for 24 trials or until the chick had not entered the goal compartment in 300 -sec on two consecutive trials.

Statistical evaluation. An analysis of variance with repeated measures was used to determine significance levels for response latencies during the acquisition and PA test trials. These analyses of variance were supplemented, when appropriate, by NewmanKeuis tests. Analyses of variance of the reciprocais of these re sponse latencies led to the same statistical interpretations, and, therefore, only analyses of latency data are presented. In addition to the analysis of response latencies, an analysis of trials to criterion for the chicks of the two ages was done using t tests.

\section{Results and Discussion}

Minimal prepunishment training. In Experiment 1, there was no significant difference between the 1 - and 4-day-old chicks in their mean step-through latency on the single acquisition trial $[\mathrm{t}(22)=.88]$. The mean step-through latencies for the 1- and 4-day-old chicks were 66.2 and $46.5 \mathrm{sec}$, respectively.

Mean step-through latencies of 1- and 4-day-old chicks across the 24 PA test trials are presented in Figure 1. The 4-day-old chicks' response latencies increased markedly over trials, whereas the 1-day-old chicks' latencies did not change significantly [Age by Trial interaction, $F(23,506)=8.75, p<.001]$. Indeed, the 4-day-old chicks' mean step-through latency on the first shock trial was $29 \mathrm{sec}$ and on the last shock trial was $300 \mathrm{sec}$. In contrast, the 1-dayold chicks' mean step-through latency on the first shock trial was $37 \mathrm{sec}$ and on the last shock trial had only increased to $60 \mathrm{sec}[\mathrm{t}(11)=.82, \mathrm{p}>.05]$.

The mean number of trials to the PA learning criterion of two consecutive $300-\mathrm{sec}$ trials and the percentage of chicks at each age reaching this criterion are presented in Table 1. There was a significant difference between the 1- and 4-day-old chicks in the mean number of trials to reach the PA learning criterion. Only one of the 1-day-old chicks reached criterion within the 24 PA test trials, whereas all of the 4-day-old chicks reached criterion. Therefore, both the latencies and the trials-to-criterion indicate that with minimal prepunishment training there is a significant age-dependent change in PA learning of the young chick when a step-through response is punished.

Extended prepunishment training. In Experiment 2, both the 1-and 4-day-old chicks' step-through

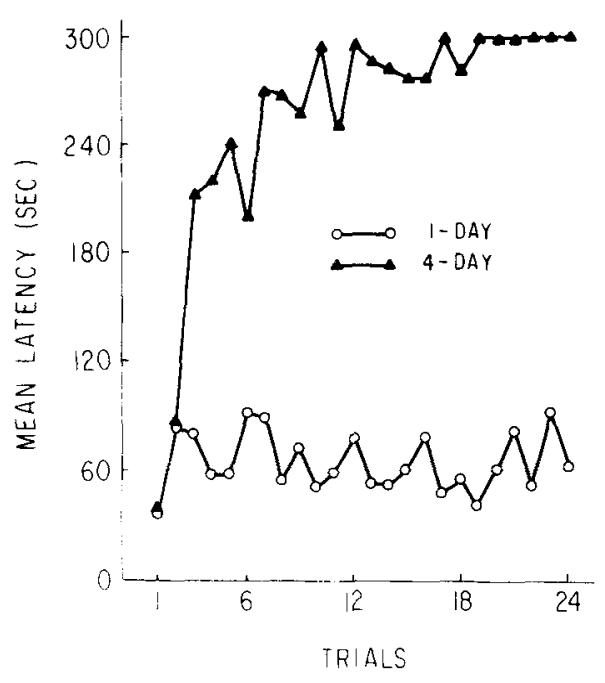

Figure 1. Mean step-through latencies per trial of 1- and 4-dayold chicks during passive avoidance testing. 
Table 1

Mean Number of Trials to PA Learning Criterion of 2 Consecutive 300-Sec Trials for 1- and 4-Day-Old Chicks and Percentage of Chicks at Each Age Reaching Criterion Within 24 Trials

\begin{tabular}{|c|c|c|c|c|c|c|}
\hline \multirow[b]{2}{*}{ Age } & \multirow{2}{*}{$\begin{array}{l}\text { Number of Acqui- } \\
\text { sition Trials }\end{array}$} & \multicolumn{2}{|c|}{ Number of Trials } & \multicolumn{2}{|c|}{ Significance Level } & \multirow{2}{*}{$\begin{array}{c}\text { Percentage } \\
\text { of Chicks }\end{array}$} \\
\hline & & Mean & $\mathrm{SE}$ & $\mathbf{t}$ & $\mathrm{p}$ & \\
\hline \multicolumn{7}{|c|}{ Experiment 1} \\
\hline $\begin{array}{l}1 \\
4\end{array}$ & 1 & $\begin{array}{r}23.8 \\
8.8\end{array}$ & $\begin{array}{r}.3 \\
1.4\end{array}$ & 14.92 & .0001 & $\begin{array}{r}8 \\
100\end{array}$ \\
\hline \multicolumn{7}{|c|}{ Experiment 2} \\
\hline $\begin{array}{l}1 \\
4\end{array}$ & 24 & $\begin{array}{l}21.5 \\
16.8\end{array}$ & $\begin{array}{l}1.2 \\
2.4\end{array}$ & 1.79 & .10 & $\begin{array}{l}33 \\
50\end{array}$ \\
\hline \multicolumn{7}{|c|}{ Experiment 3} \\
\hline $\begin{array}{l}1 \\
4\end{array}$ & 24 & $\begin{array}{l}18.7 \\
11.6\end{array}$ & $\begin{array}{l}1.8 \\
1.7\end{array}$ & & .05 & $\begin{array}{l}50 \\
92\end{array}$ \\
\hline $\begin{array}{l}1 \\
4\end{array}$ & 48 & $\begin{array}{l}17.6 \\
18.2\end{array}$ & $\begin{array}{l}1.7 \\
2.0\end{array}$ & & n.s. & $\begin{array}{l}67 \\
50\end{array}$ \\
\hline
\end{tabular}

Note-Significance levels for Experiments 1 and 2 are based on two-tailed t tests $(d f=22)$; those for Experiment 3 are based on individual Newman.Keuls tests of the significant Age by Acquisition interaction ( $p<$ value listed).

latencies decreased significantly across the 24 acquisition trials $[F(23,506)=7.06, p<.001]$, and there were no significant differences between the chicks of the two age groups in this latency decrease.

Following the onset of shock, chicks of both ages increased step-through latencies $[F(23,506)=6.33$, $\mathrm{p}<.0001]$, the overall age difference was marginally significant $[F(1,22)=3.98, p<.06]$, and the interaction was not significant $[F(23,506)=1.06]$.

The mean number of trials to the PA learning criterion and the percentage of chicks at each age reaching this criterion are also presented in Table 1. The 1- and 4-day-old chicks did not differ significantly in their mean number of trials to reach criterion. Interestingly, although the PA learning of the 1-dayold chicks showed a slight improvement after 24 acquisition trials when compared with their performance after only one acquisition trial in Experiment 1, the PA learning of the 4-day-old chicks showed a significant deterioration after 24 acquisition trials when compared with their performance after only one acquisition trial (Table 1). Apparently, therefore, increasing acquisition training from 1 to 24 trials made the 4-day-old chick more resistant to punishment and, consequently, retarded PA learning.

\section{EXPERIMENT 3}

The interpretation of the significant step-through PA learning difference between 1- and 4-day-old chicks found after one prepunishment trial but not after 24 prepunishment trials is complicated by the apparent increase in resistance to punishment of the 4-day-old chicks as the number of prepunishment trials was increased. The significant acquisition effects on the age dependency of PA learning in both keypeck and runway tests were assumed to occur because the young chick was deficient in learning, or detecting changes in, stimulus- and/or responsereinforcement contingencies. Increased prepunishment training, therefore, was thought to increase the 1-day-old chick's sensitivity to these contingencies to a level comparable to that of the 4-day-old chick before punishment was introduced (Mattingly \& Zolman, 1980). However, an increase in the number of prepunishment trials in a step-through PA test also appeared to increase resistance to punishment in the 4-day-old chick but not in the 1-day-old chick. Apparently, then, the young chick's performance during PA testing would be a function of both its sensitivity to changes in reinforcement contingencies and its resistance to punishment. The purpose of Experiment 3 was to determine the effects of increasing both the number of prepunishment trials and the distinctiveness of the safe and shock compartments on the age-dependency of step-through PA learning of the young chick. Distinct cue differences between the safe and shock compartments should facilitate the chicks' learning of the stimulus-reinforcement contingencies. In Experiment 3, 1- and 4-day-old chicks were first given either 24 or 48 acquisition trials, in which they were required to move from a white into a vertical-striped compartment to receive heat reward. Following this acquisition training, the chicks' entrance into the vertical-striped compartment was punished by wing shocks.

\section{Method}

Forty-eight Vantress $\times$ Arbor Acre chicks were incubated, hatched, and reared under the same conditions as described in Experiment 1. Twenty-four chicks began testing when 1 day old $(22.3 \mathrm{~h} ; \mathrm{SD}=1.02)$, and the remainder began testing when 4 days old $(100.2 \mathrm{~h} ; \mathrm{SD}=2.57)$. Prior to PA testing, one-half of the chicks of each age were given 24 acquisition trials and the rest were given 48 acquisition trials. The apparatus and procedure were the same as in the preceding experiments, except: (1) an $11 \times 29 \mathrm{~cm}$ white cardboard insert with three vertical 2 -cm black stripes spaced $2.5 \mathrm{~cm}$ apart was placed $2.5 \mathrm{~cm}$ from the wall of the goalbox 
facing the door; and (2) chicks in the 48-trial acquisition group were returned to the brooder room and isolated in the plastic tubes for 15 -min following the 24th acquisition trial.

\section{Results and Discussion}

Because of the unequal number of prepunishment trials, analyses of variance were performed separately for the 24- and 48-acquisition trial groups. Chicks in both the 24- and 48-trial groups significantly decreased step-through latencies across prepunishment trials $[F(23,506)=23.92, p<.001$, and $F(47,1034)=$ $31.48, \mathrm{p}<.0001$, respectively]. In both acquisition groups, the 1-day-old chicks had slower initial stepthrough latencies than did the 4-day-old chicks, but within 24 trials chicks of both ages were responding at about the same speed.

Mean step-through latencies across the 24 PA trials for the 1- and 4-day-old chicks given different acquisition training are presented in Figure 2. Both the 1and 4-day-old chicks showed a significant increase in step-through latencies following the onset of punishment [trial effect, $F(23,1012)=25.54, p<.0001$ ] Furthermore, the 4-day-old chicks increased stepthrough latencies more quickly than did the 1-dayold chicks after 24 acquisition trials, but there was no significant difference between the 1- and 4-day-old chicks in step-through latencies during PA testing when 48 acquisition trials were given (see Figure 2). Thus, neither the main effect of age $[F(1,23)=1.71]$ nor number of acquisition trials $[F(1,23)=1.27]$ approached significance, but both the Age by Acquisition and the Age by Acquisition by Trial interactions were significant $[F(1,44)=7.26, p<.01$, and $F(23,1012)=$ $2.79, \mathrm{p}<.0001$, respectively].

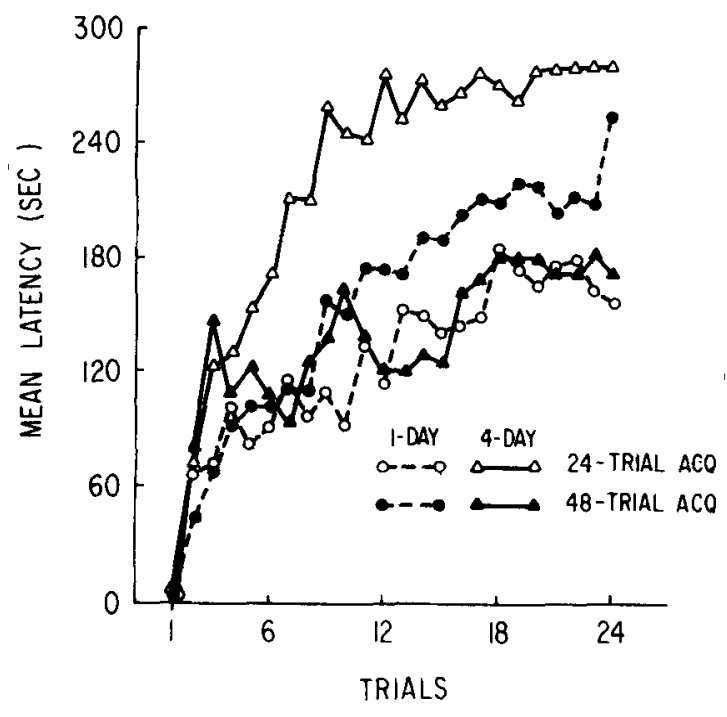

Figure 2. Mean step-through latencies per trial of 1- and 4-dayold chicks given either 24- or 48-acquisition (ACQ) trials prior to passive avoidance testing.

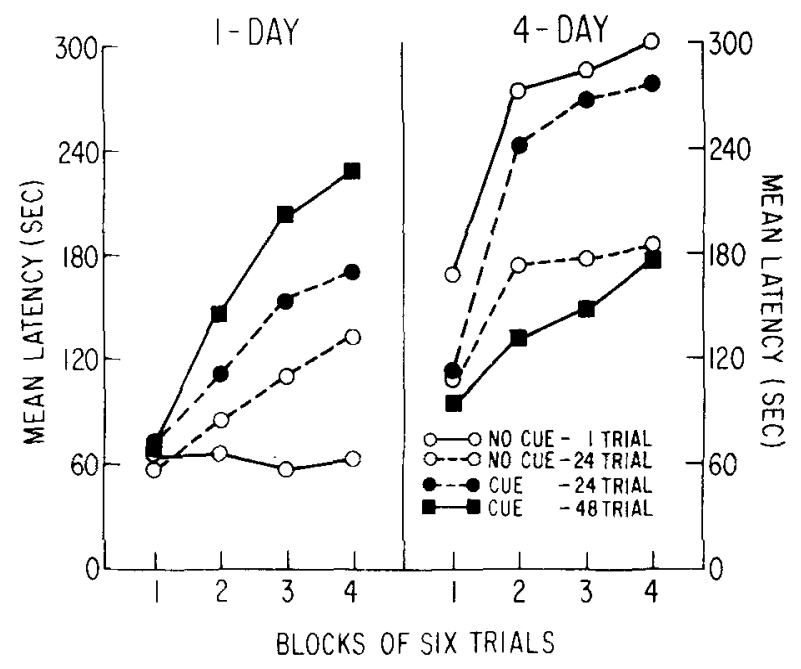

Figure 3. Mean step-through latencies per trial across blocks of six passive avoidance trials for 1-and 4-day-old chicks trained and tested with or without distinctive shock compartment cues and given 1, 24, or 48 acquisition trials prior to passive avoidance testing.

The mean number of trials to the PA learning criterion for the 1- and 4-day-old chicks in each acquisition group and the percentage of chicks in each group reaching criterion are presented in Table 1 . The ANOVA of the trials to criterion data also revealed neither an age effect $[F(1,44)=3.13]$ nor an acquisition effect $[F(1,44)=2.37]$, but did show a significant Age by Acquisition interaction $[F(1,44)=$ $4.56, \mathrm{p}<.05$ ]. Newman-Keuls tests showed that, after 24 acquisition trials, the 1-day-old chicks required more trials to reach the PA learning criterion than did the 4-day-old chicks $(p<.05)$, but that after 48 acquisition trials there was no difference between the 1- and 4-day-old chicks. Also, although there was no significant difference in mean criterion trials for the 1-day-old chicks given either 24 or 48 prior acquisition trials, the 4-day-old chicks given 48 acquisition trials required more trials to reach criterion than did the 4-day-old chicks given only 24 acquisition trials.

Comparisons across the three PA experiments are required to evaluate the combined effects of prepunishment training and cue differences between compartments on the age-dependency of PA learning of the young chick. Therefore, mean step-through latencies across six trial blocks for all of the 1- and 4-day-old chicks are presented in Figure 3. For the 1-day-old chicks, the effects of cue distinctiveness and the number of prepunishment trials were additive. With distinct cues in the shock compartment and the greatest number of prepunishment trials, the 1-day-old chicks showed the greatest increase in stepthrough latencies when punished (Experiment 3). Conversely, with identical cues in both compartments and after only one prepunishment trial, the 1day-old chicks showed only a slight increase in their 
step-through latencies when punished (Experiment 1). With the same cues in both compartments, an increase in the number of prepunishment trials increased the PA learning of the 1-day-old chick (Experiments 1 and 2).

In contrast with this additive relation between cue distinctiveness and the number of prepunishment trials on PA learning of the 1-day-old chick, a significant interaction between these two variables was found for the 4-day-old chick. With identical cues in both compartments and after only one prepunishment trial, the 4-day-old chicks showed a rapid increase in step-through latencies when punished (Experiment 1). Similarly, with distinct cues in the shock compartment and after 24 prepunishment trials, the 4-day-old chicks showed a rapid increase in their stepthrough latencies when punished (Experiment 3). However, PA learning of the 4-day-old chicks was retarded by an increase in the number of prepunishment trials when either identical (Experiment 1 and 2) or distinct (Experiment 3 ) cues were in the two compartments.

\section{GENERAL DISCUSSION}

It is evident that age-dependent differences in PA learning of the young chick depend upon both the cue differences between safe and shock compartments and the number of prepunishment training trials. Increasing both cue distinctiveness and prepunishment trials has an additive effect on the rate of PA learning of the 1-day-old chick but has an interactive effect on the rate of PA learning of the 4day-old chick.

Since step-through PA learning in the adult animal has been shown to be based on both stimulus- and response-shock contingencies (e.g., Randall \& Riccio, 1969), greater cue differences between safe and shock compartments would be expected to improve the young chick's PA learning. Also, as prepunishment training is increased, the adult animal's resistance to punishment usually increases initially and then decreases as more prepunishment training is given (Born, 1967; Karsh, 1962). For the 4-day-old chick, an increase in prepunishment training under both stimulus conditions apparently led to greater resistance to punishment and, consequently, retarded PA learning. But, for the 1-day-old chick, increased prepunishment training under both stimulus conditions resulted in better PA learning.

Although it is not presently clear why increasing the amount of prepunishment training improves the 1-day-old chick's PA learning, the absence of a delayed-punishment effect on the 1-day-old chick's keypeck PA performance following brief prepunishment training supports an associative-deficiency interpretation (see Mattingly \& Zolmon, 1980)specifically, that the 1-day-old chick is deficient in learning, or detecting changes in, the appropriate stimulus- and/or response-reinforcement contingencies. Increasing the amount of prepunishment training was assumed, therefore, to increase the 1-day-old chick's sensitivity to these contingencies to a level comparable to that of the 4-day-old chick.

Recent studies on the effects of home environmental cues on age-dependent changes in locomotor activity, spontaneous alternation, and PA learning in the young rat (Campbell \& Raskin, 1978; Smith \& Spear, 1978) suggest, however, that the presence of familiar cues may enable the immature animal to use more of the cues or learning strategies used by adults in learning to withhold responses. Extended prepunishment training may, therefore, reduce nonspecific arousal induced by unfamiliar surroundings and thereby permit the 1-day-old chick to learn the significant contingencies during subsequent PA testing. If so, then this would be another case in which the learning of the immature animal is affected by familiar and unfamiliar environmental contextual cues while the slightly older, but still developing animal, is not so affected (see Infurna, Steinert, \& Spear, 1979).

\section{REFERENCES}

Born, D. G. Resistance of a free operant to extinction and suppression with punishment as a function of amount of training. Psychonomic Science, 1967, 8, 21-22.

Campbell, B. A., \& Coulter, X. The ontogenesis of learning and memory. In M. R. Rosenzweig \& E. L. Bennett (Eds.), Neural mechanisms of learning and memory. Cambridge, Mass: M.I.T. Press, 1976.

Campbell, B. A., \& RAskin, L. A. Ontogeny of behavioral arousal: The role of environmental stimuli. Journal of Comparative and Physiological Psychology, 1978, 92, 176-184.

Infurna, R. N., Steinert, P. A., \& Spear, N. E. Ontogenetic changes in the modulation of taste aversion learning by home environmental cues in rats. Journal of Comparative and Physiological Psychology, 1979, 93, 1097-1108.

KARSH, E. B. Effects of number of rewarded trials and intensity of punishment on running speed. Journal of Comparative and Physiological Psychology, 1962, 55, 44-51.

Mattingly, B. A., \& Zolman, J. F. Ontogeny of passive avoidance learning in domestic chicks: Punishment of key-peck and running responses. Journal of Comparative and Physiological Psychology, 1980, 94, 718-733.

Randall, P. K., \& Riccio, D. C. Fear and punishment as determinants of passive avoidance responding. Journal of Comparative and Physiological Psychology, 1969, 69, 550-553.

Riccio, D. C., \& Schulenberg, C. J. Age-related changes in acquisition of a passive avoidance response. Canadian Journal of Psychology, 1969, 23, 429-437.

Schulenberg, C. J., Riccio, D. C., \& Stikes, E. R. Acquisition and retention of a passive-avoidance response as a function of age in rats. Journal of Comparative and Physiological Psychology, 1971, 74, 75-83.

Smith, G. J., \& SPEAR, N. E. Effects of the home environment on withholding behaviors and conditioning in infant and neonatal rats. Science, 1978, 202, 327-329.

Wilson, L. M., \& Riccio, D. C. Scopolamine's effect on passive avoidance behavior in immature rats. Developmental Psycho. biology, 1976, 9, 245-254.

(Received for publication August 14, 1980; revision accepted December 30, 1980.) 